Dicle University Journal of Engineering (DUJE)

\title{
Pazar Yerinde Gürültüi Kirliliğinin Belirlenmesi: Bursa İli Örneği
}

\section{Determination of Noise Pollution in Market Place: Bursa Case Study}

\author{
Melike Yalılı Kılıç*, Sümeyye Adalı ${ }^{1}$ \\ ${ }^{1}$ Bursa Uludağ Üniversitesi, Çevre Mühendisliği Bölümü, Bursa, \\ e-mail: myalili@uludag.edu.tr (M.Yalı1ı Kılıç), 501904007@ogr.uludag.edu.tr (S. Adalı), Tel: 0-224-294 2117
}

\begin{tabular}{|c|c|}
\hline MAKALE BİLGİLERİ & ÖZET \\
\hline Makale geçmişi: & \multirow{6}{*}{ 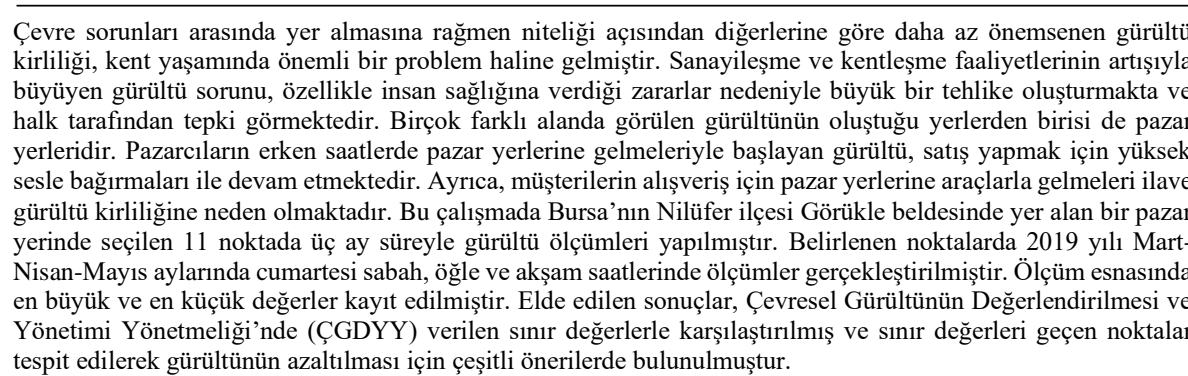 } \\
\hline Geliş: 13 May 2020 & \\
\hline & \\
\hline Kabul: 17 Eylül 2020 & \\
\hline Anahtar kelimeler: & \\
\hline $\begin{array}{l}\text { Bursa, çevre kirliliği, gürültü, pazar } \\
\text { yeri, yerleşim alanı }\end{array}$ & \\
\hline
\end{tabular}

Doi: $10.24012 /$ dumf. 736027

\begin{tabular}{|c|c|}
\hline ARTICLE INFO & ABSTRACT \\
\hline Article history: & \multirow{6}{*}{$\begin{array}{l}\text { Although it is among the environmental problems, noise pollution, which is less important in terms of quality than } \\
\text { others, has become an important problem in urban life. The noise problem, which grows with the increase in } \\
\text { industrialization and urbanization activities, poses a great danger and is reacted by the public, especially due to } \\
\text { the damages it causes to human health. One of the places where noise occurs in many different areas is } \\
\text { marketplaces. The noise, started with the sellers coming to the marketplace in the early hours, continues with the } \\
\text { loud shouts of sellers. In addition, customers' coming to the marketplaces by their vehicles for shopping cause } \\
\text { additional noise pollution. In this study, noise measurements were carried out for three months at } 11 \text { points selected } \\
\text { in a marketplace located in the Görükle, Nilüfer district of Bursa. In the determined points, measurements were } \\
\text { made on Saturday morning, lunch and evening hours in March-April-May } 2019 \text {. During the measurement, the } \\
\text { largest and smallest values were recorded. The results obtained were compared with the limit values given in the } \\
\text { Regulation on the Assessment and Management of Environmental Noise (RAMEN) and various suggestions were } \\
\text { made to reduce noise by determining the points exceeding the limit values. }\end{array}$} \\
\hline Received: 13 May 2020 & \\
\hline Revised: 15 September 2020 & \\
\hline Accepted: 17 September 2020 & \\
\hline Keywords: & \\
\hline $\begin{array}{l}\text { Bursa, environmental pollution, } \\
\text { noise, market place, residential } \\
\text { area }\end{array}$ & \\
\hline
\end{tabular}

* Sorumlu yazar / Correspondence

Melike YALILI KILIÇ

$\triangle$ myalili@uludag.edu.tr 


\section{Giriș}

Maddelerin hareket halindeyken havada oluşturduğu basınç salınımlarına ses, sesin canlılar üzerinde zararlı etkiler oluşturabilecek seviyede olma durumuna gürültü denir [1]. Gürültü genellikle ulaşım, sanayi, imar çalışmaları ve yerleşim yerlerindeki insan kaynaklı faaliyetler sonucu oluşur [2]. Gündelik yaşamda insanlar bulundukları ortamlarda birden fazla gürültü kaynağına maruz kalmaktadır $[3,4]$. Sanayileşme ve kentleşme faaliyetleri ile gittikçe artan gürültü sorunu, hayat kalitesini ve çevreyi olumsuz yönde etkilemektedir [5,6]. Toplumlara göre farklılıklar görülmesine rağmen, gürültü seviyesinin genellikle 55 dBA'yı aşması durumunda insanlarda rahatsızlık hissi oluşturduğu bildirilmektedir [2].

Gürültü, sağlık üzerinde birçok olumsuz etki oluşturmaktadır. Gürültünün oluşturduğu fizyolojik etkiler arasında işitme sorunları, kalp atışının hızlanması, metabolik bozukluklar, uyku bozukluğu; psikolojik etkiler arasında sinir sisteminin bozulması, hoşnutsuzluk, tedirginlik hissi; performans etkileri arasında iş verimi ve konforunda azalma, dinleme ve anlamada güçlük çekme, konsantrasyon bozukluğu yer almaktadır [7,8]. Gürültü, özellikle sanayi faaliyetlerinin yoğun olarak gerçekleştirildiği ülkelerde işitme kaynaklı meslek hastalıklarının ortaya çıkmasına ve çalışanların yaşam kalitesinde düşüşe neden olmaktadır [9,10].

Oluşturduğu olumsuz etkiler nedeniyle son dönemlerde üzerinde çalışılan çevre sorunlarından biri olan gürültü kirliliğinin belirlenmesi amaciyla, farklı ortamlarda ve sektörlerde yapılmış pek çok çalışma bulunmaktadır [11]. Gürültü ölçümleri gerçekleştirilen ortamlar arasında hastane [12,13], okul [14,15], iş yerleri [16-18], farklı alanlarda hizmet veren endüstriyel işletmeler [19-21], yerleşim yerleri [22,23] ve ulaşım faaliyetlerinin yürütüldüğü alanlar [24-27] yer almaktadır.

Kentleşme faaliyetlerinin başlamasıyla beraber ortaya çıkan pazar yerleri, kamusal alan ve yaya bölgesi olarak sınıflandırılmakla birlikte günün her saatinde yoğun olarak kullanılmaktadır
[28,29]. Çoğunlukla tarım ürünlerinin satışının gerçekleştiği pazar yerleri tarımsal üretimin sürdürülmesi ve güçlenmesine katk1 sağlamaktadır [30]. Topluma ekonomik ürünlerin temininde oldukça önemli bir rol üstlenen pazar yerlerinde, çevreye verilen gürültü günün değişik zaman dilimlerinde yüksek seviyelerde seyredebilmektedir. Kurulduğu bölgede trafik yoğunluğu oluşturması, satış yapan pazarcıların müşterilerine yüksek sesle ürünlerini sunmaları, pazar yerlerinde oluşan gürültü seviyesinin artarak devam etmesine yol açmaktadır.

Çalışkan [31]'ın Bursa'daki pazar yerleri ve sorunlarını ele aldığı çalışmasında gürültünün bu alanlarda problem teşkil ettiği belirtilmektedir. Yağbasan ve Canpolat [32] yaptıkları çalışmada pazar yerlerinden kaynaklanan gürültünün eğitim-öğretim ortamına olumsuz etkide bulunduğunu ve pazarcıların ürünlerinin satışını gerçekleştirmek için yaptıkları bağırma eyleminin halk tarafından olumsuz karşılandığını ifade etmişlerdir. Dalyan belediyesi yaz döneminde belde merkezindeki trafik ve nüfus yoğunluğunu arttırması nedeniyle merkezdeki pazar yerini taşıma kararı almıştır [33]. Yerli [29], Düzce kentinde yaptığı çalışmada 1 yıllık süre boyunca pazar yerinde birbirine eşit mesafede bulunan 6 noktada haftalik olarak gerçekleştirdiği ölçümlerle oluşan gürültüyü belirlemiştir. Ölçüm sonuçları aylık bazda karşılaştırıldığında en yüksek ortalama değer 70 dBA değeri ile ağustos, en düşük ortalama değer 56 dBA değeri ile aralık ayında hesaplanmıştır.

Ülkemizde gürültü kirliliği ile ilgili hazırlanan ilk çalışma 11 Aralık 1986'da yayınlanan “Gürültü Kontrol Yönetmeliği”dir [34]. Günümüzde ise, Çevresel Gürültünün Değerlendirilmesi ve Yönetimi Yönetmeliği (ÇGDYY) olarak geçerliliğini koruyan yönetmelikte birçok alanda olduğu gibi, kentlerdeki donatı alanlarından biri olan ve bu çalışmanın ana konusunu teşkil eden pazar yerleri için insan ve çevre sağlı̆̆ını korumak amacıyla gürültü sınır değerleri belirlenmiştir. 
Bu çalışmada, Bursa ili Nilüfer ilçesi Görükle yerleşim yerinde bulunan bir pazar yerinden kaynaklanan gürültünün belirlenmesi amacıyla, 11 noktada gürültü ölçümleri gerçekleştirilmiş ve ve elde edilen sonuçlar ÇGDYY'deki sınır değerlerle karşılaştırılarak, bu değerlerin sağlanıp sağlanamadığı belirlenmiştir.

\section{Materyal ve Metot}

Yerleşim yerlerinde çeşitli faaliyetler sonucu oluşan gürültü kirliliği, toplumda ve özellikle kent yaşamında ciddi problem teşkil etmektedir. Bu nedenle birçok ülkede olduğu gibi ülkemizde de hazırlanan yönetmelik ve yapılan düzenlemelerle gürültü kirliliği kontrol altına alınmaya çalışılmaktadır. Bu çalışmada ele alınan yerleşim alanı Görükle, Bursa'nın Nilüfer ilçesine bağlı eski bir köydür. Köyün sınırları içerisinde bulunan üniversite dolayısıyla özellikle son y1llarda büyük bir büyüme göstermiştir. Eski bir Rum köyü olan Görükle, Yeşil Cami'nin vakıf köyüdür. İşgal yıllarında tahrip edilen Görükle'ye, savaş sonunda Rumların kenti terk etmesiyle, 1924 yılında Yunanistan'ın Langaza kazasının çeşitli köylerinden ve diğer bölgelerden gelen göçmenler yerleştirilmiştir. 1955 yılında bucak, 1957 yılında belde olan Görükle'de belediye örgütü kurulmuştur. Görükle'ye ait üç bin dönüm mera, 1988 y1lında Bursa Büyükşehir Belediyesine dahil olduktan sonra istimlak edilerek, bir kısmına Uludağ Üniversitesi kampüsü kurulmuştur [35]. Öğrencilerin eğitimleri süresince üniversiteye yakın olmas1 nedeniyle yaşamayı tercih etmeleri dolayısıyla, Görükle genç nüfus oranının yüksek olduğu bir yerleşim bölgesidir. Görükle'nin merkezinde yer alan pazarın çevresinde birden fazla sağlık (veteriner kliniği, sağlık ocağı) ve eğitim kurumu (ilkokul, öğretim kursu, sürücü kursu) ile kırtasiye, emlak, oto y1kama, lokanta, market, eczane, butik vb. birçok ticari işletme yer almaktadir.

$\mathrm{Bu}$ çalışmada, Bursa ili Nilüfer ilçesine bağlı Görükle semtinde kurulan pazar yerinden kaynaklanan gürültünün belirlenmesi amaciyla, pazar alanında ve pazar yerinin çevresinde park alanlarını sınırlayan trafik yollarına yakın noktalarda gürültü ölçümleri yapılmıştır.

Belirlenen bu noktalarda 2019 y1l Mart-NisanMayıs aylarında cumartesi günü kurulan pazar yerinde sabah, öğle ve akşam saatlerinde ölçümler yapılmıştır. Yaklaşık 3 bin $150 \mathrm{~m}^{2}$ lik alanda kurulu bulunan [36] pazar yeri ve çevresinin uydu görüntüsü ile gürültü ölçümü yapılan noktalar Şekil 1'de gösterilmiştir.

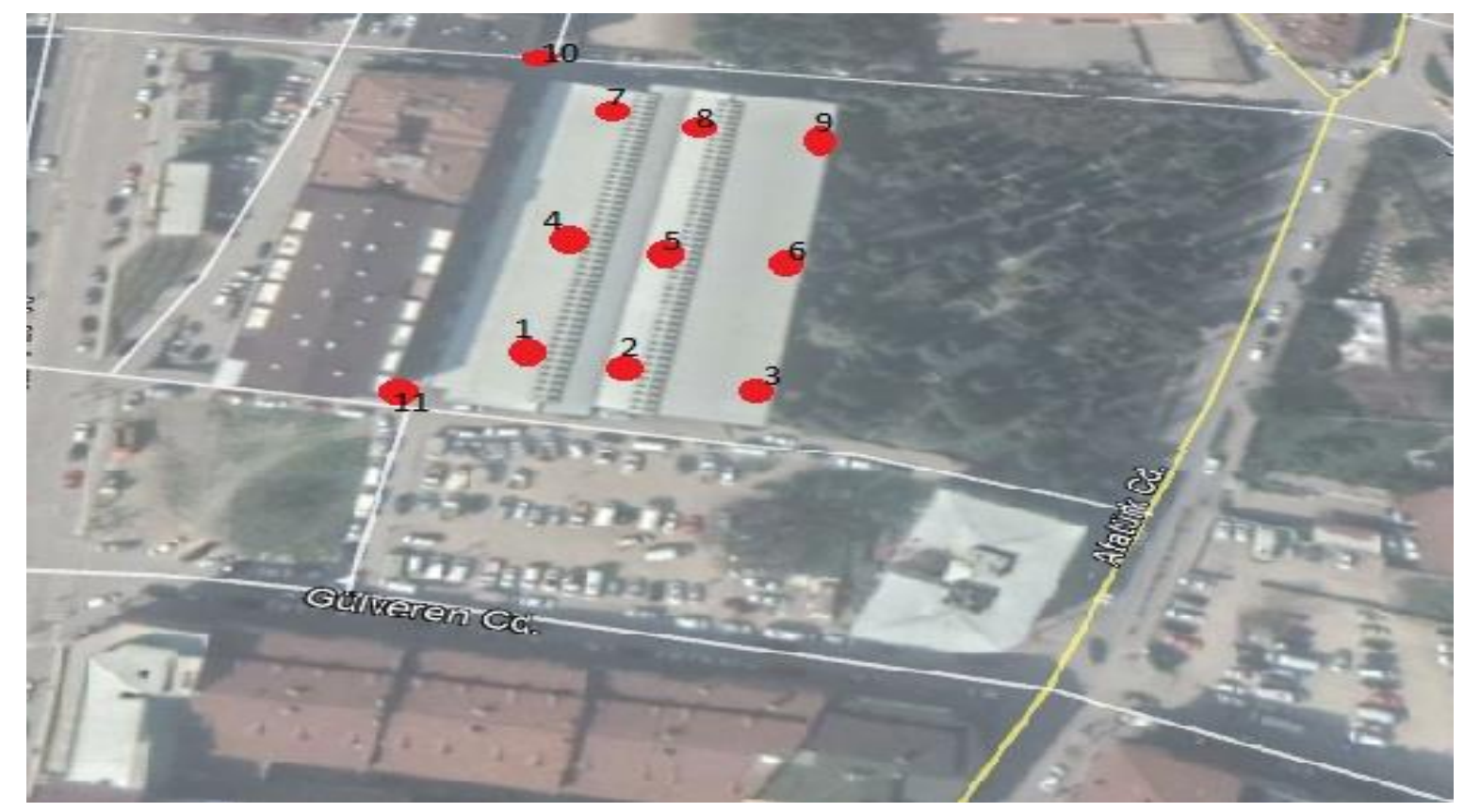

Şekil 1. Görükle pazar yeri ve çevresi [37] 
Dikdörtgen olarak inşa edilmiş yapı içerisinde ölçüm alınan noktalarda, kısa kenar üzerindeki noktalar arasında yaklaşık $16 \mathrm{~m}$; uzun kenar üzerindeki noktalar arasında yaklaşık $44 \mathrm{~m}$ mesafe vardır. Yapı dıșında seçilen noktaların yapıya olan uzaklığ 1 yaklaşı 10 m'dir. Ölçümler, sabah 08.00-09.00, öğlen 12.00-13.00 ve akşam 17.00-18.00 saatlerinde 3'er dakikalık periyotlar halinde yapılmıştır. Ölçüm esnasında en büyük ve en küçük değerler kayıt edilmiştir. Gürültü ölçümleri 1.2 metre yükseklikten, zeminle $\quad 45^{\circ}$ açı oluşturacak şekilde gerçekleştirilmiştir [38]. Ölçümlerin hava şartlarından etkilenmemesi amacıyla rüzgarın hafif olduğu ve yağıșın olmadığı günlerde ölçümler yapılmıştır. Ölçüm esnasında olağan dışı gürültü durumları not edilmiş, bu gibi durumlarda ölçümler tekrarlanmıştır. Sabah ve öğle ölçümü yapıldıktan sonra, eğer akşam yağmurlu veya rüzgarlı bir hava olursa bütün bir günün ölçümü iptal edilmiştir. Çalışmada gürültü ölçümleri için EXTECT 407738 ses ölçüm cihazı kullanılmıştır (Şekil 2).

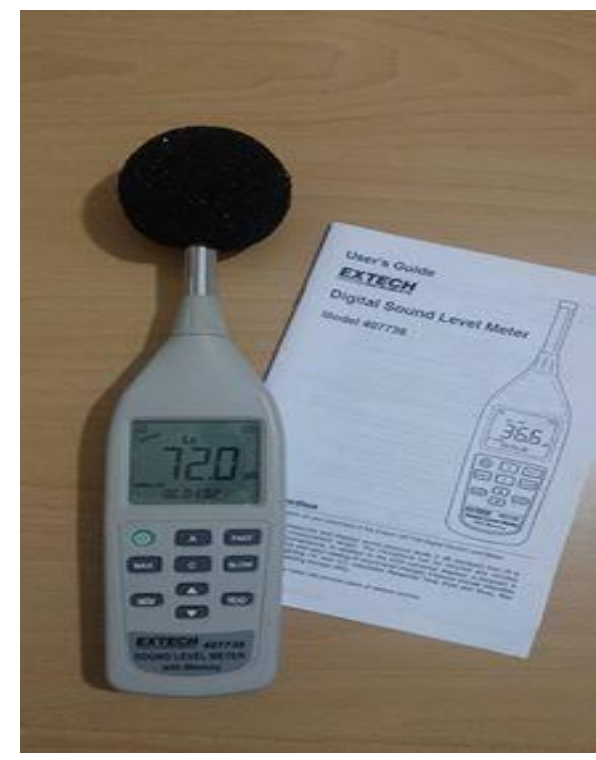

Şekil 2. Ölçüm cihazı

Alınan ölçümler maksimum eşdeğer gürültü düzeyi (Leq ${ }_{\max }$ ) cinsinden ve $\mathrm{A}$ ağırlıklı ses düzeyi (dBA) birimindendir. Gürültü yansımasını engellemek amaciyla bina, duvar, ağaç gibi yapay ve doğal nitelikteki yapıların 1.5 metre kadar uzağında ölçümler yapılmıştır.
Ölçümler aynı nokta ve pozisyonlarda alınarak kaydedilmiştir.

\section{Bulgular ve Tartışma}

Birinci ölçüm noktası Görükle Semt Pazarı giriş noktasıdır. Bu noktadaki maksimum değer 72.6 dBA olup, 13.04.2019 tarihinde sabah saatlerinde (08.00-09.00) ölçülmüştür. Ölçülen bu gürültü, sabah saatlerinde pazar ürünlerinin pazar yerine nakli, pazar tezgahlarının kurulup ürünlerin yerleștirilmesi ve erken saatlerde alışveriş yapmak isteyen müşterilerin araç giriş çıkışları ile insan seslerinden kaynaklanmaktadır. ÇGDYY'de mevcut yollarda ticari yapılar ile konutların yoğun olarak bulunduğu alanlar için verilen sınır değerler gündüz $68 \mathrm{dBA}$, akşam $63 \mathrm{dBA}$ 'dır. Bu sınır değerlerin birinci noktada yapılan tüm ölçümlerde aşıldığı görülmektedir (Şekil 3).

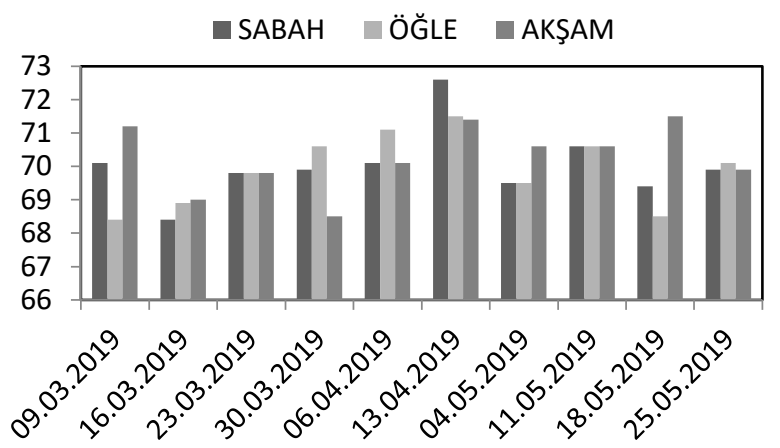

\section{Şekil 3. Birinci noktada ölçülen maksimum gürültü değerleri}

İkinci ölçüm noktası, pazar yeri girişinden bir sonraki nokta olup aynı hizadaki orta noktadır. Bu noktada ölçülen maksimum değer 13.04.2019 tarihinde sabah saatlerinde (08.00-09.00) 70.4 dBA'dır (Şekil 4). Ölçülen bu gürültü değeri, pazarda bulunan insanların seslerinden ve ölçüm noktasının pazar yeri girişine olan yakınlığından kaynaklanmaktadır. Bu nokta girișe yakın olduğu için araç seslerinin de ölçülen gürültüye etkisi olmuștur. Ölçüm sonuçları değerlendirildiğinde gündüz ölçümlerinin çoğunun, akşam ölçümlerinin ise tamamının ÇGDYY'de verilen (gündüz $68 \mathrm{dBA}$, akşam $63 \mathrm{dBA}$ ) sınır değerleri sağlayamadığ 1 belirlenmiştir. 


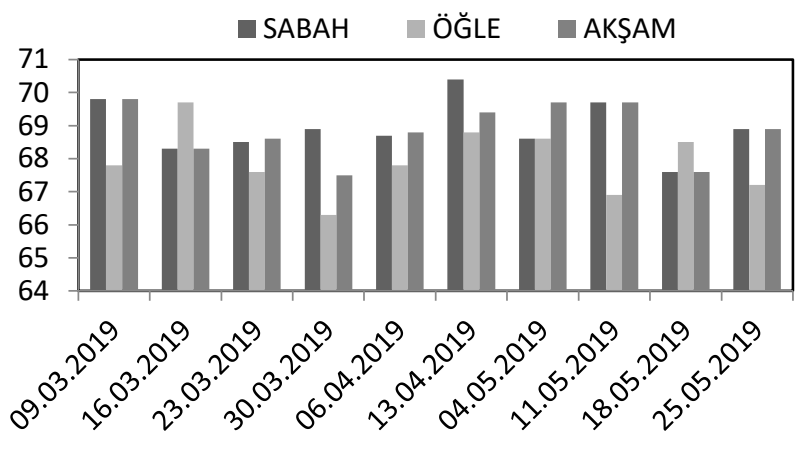

Şekil 4. Íkinci noktada ölçülen maksimum gürültü değgerleri

Görükle Semt Pazarı içerisindeki üçüncü nokta giriş hizasında köşe noktadır. Bu noktada ölçülen maksimum değer 13.04.2019 ve 04.05.2019 tarihlerinde akşam saatlerinde (17.00-18.00) 69.9 dBA olarak ölçülmüştür (Şekil 5). Ölçülen bu gürültü değeri genel olarak pazarda satış yapan pazarciların seslerinden kaynaklanmaktadır. Bu nokta pazar yerinin köşe noktası olduğu için gürültünün fazla olmadığı bir nokta olup, ölçülen değerlerin gündüz $68 \mathrm{dBA}$, akşam 63 dBA olarak ÇGDYY'de verilen sınır değerlerin akşam vakitlerindeki tüm ölçümler boyunca sağlanamadığı, gündüz vakitlerindeki ölçümlerin çoğunun ise sınır değerin altında kaldığı belirlenmiştir.

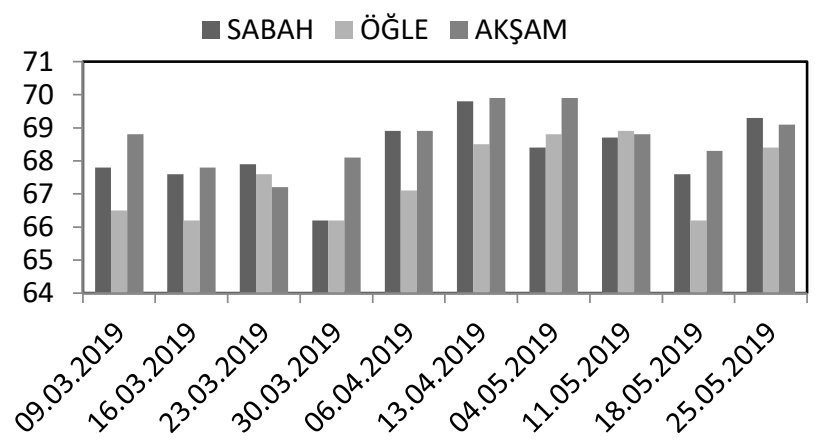

Şekil 5. Üçüncü noktada ölçülen maksimum gürültü değerleri

Görükle Semt Pazarı içerisindeki dördüncü nokta pazar yerinin orta kısmı hizasında diğer bir köşe noktasıdır. Bu noktada ölçülen maksimum değer 04.05.2019 tarihinde akşam saatlerinde (17.0018.00) $70.1 \mathrm{~dB}(\mathrm{~A})$ 'dır (Şekil 6). Şekil 6 incelendiğinde, ÇGDYY'de gündüz $68 \mathrm{dBA}$, akşam 63 dBA olarak verilen sınır değerlerin gündüz ölçümlerinin çoğunda, akşam ölçümlerinin ise tamamında aşıldı̆̆ görülmektedir.

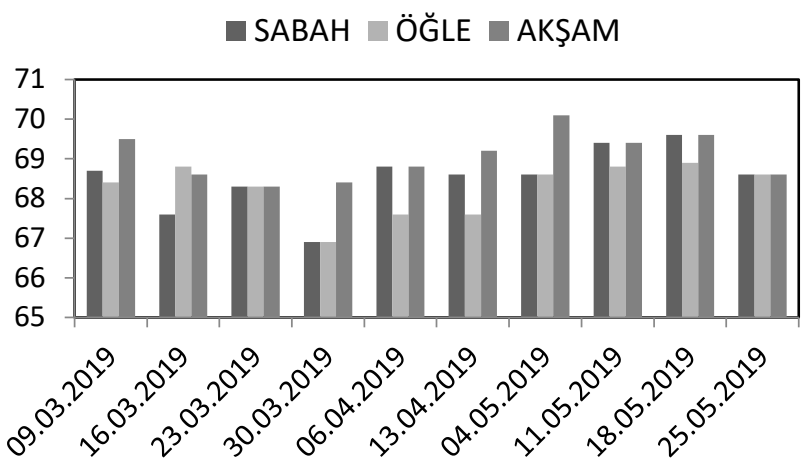

\section{Şekil 6. Dördüncü noktada ölçülen maksimum gürültü değerleri}

Görükle Semt Pazarı içerisindeki beşinci nokta pazar yerinin tam orta noktasıdır. Pazar yerinde oluşan gürültünün asıl kaynağı alışveriş için gelen insanlar ile satış yapan pazarcılar olduğu için, bu nokta ses yoğunluğunun en fazla görüldüğü noktadır. Bu noktadaki ölçüm sonuçları Şekil 7'de verilmiş olup; ölçülen maksimum değer 30.03.2019 tarihinde öğle saatlerinde (12.00-13.00) 80.7 dBA olarak elde edilmiştir. Şekil 7 incelendiğinde, gündüz 68 dBA, akşam 63 dBA olarak ÇGDYY'de verilen sınır değerlerin yapılan ölçümlerin tamamında aşıldığ görülmektedir.

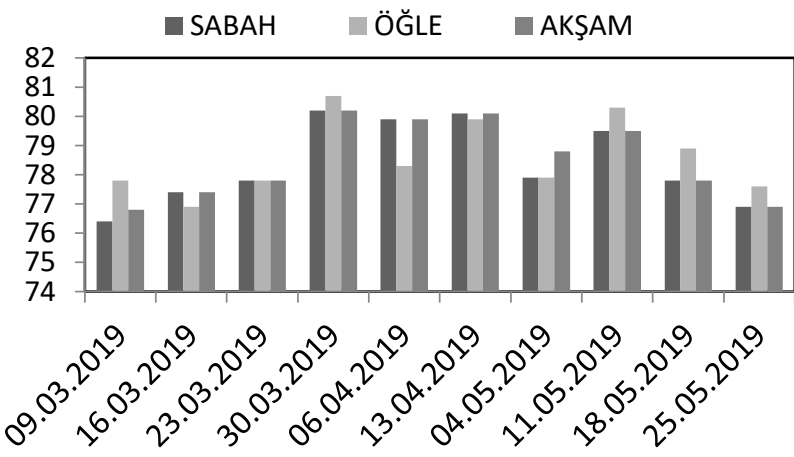

\section{Şekil 7. Beşinci noktada ölçülen maksimum gürültü değerleri}

Altıncı ölçüm noktası pazar yerinin orta kısmı hizasında köşe noktasıdır. Bu nokta pazar yerinin orta kısmında bulunduğu için ses yoğunluğunun fazla olduğu gözlemlenmiş olup, ölçülen maksimum değer 04.05.2019 tarihinde akşam saatlerinde 74.3 dBA'dır (Şekil 8). Gündüz 68 dBA olan sınır değerin sadece 09.03.2019 öğle ölçümünde aşılmadığı, ancak akşam 63 dBA 
olarak verilen sınır değerin tüm ölçümlerde aşıldığ 1 görülmektedir.

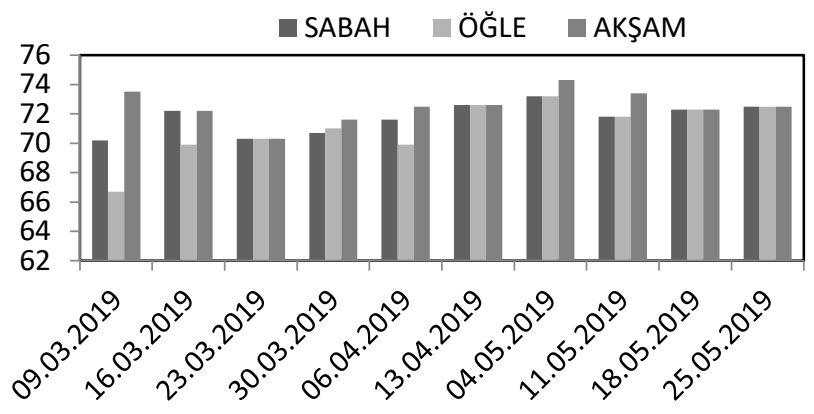

\section{Şekil 8. Altıncı noktada ölçülen maksimum} gürültü değerleri

Pazar yerinin bitiş kısmında köşe noktada yer alan yedinci ölçüm noktasında ölçülen maksimum değer 09.03.2019 ve 04.05.2019 tarihlerinde akşam saatlerinde 67.8 dBA'dır (Şekil 9). Bu noktadaki gürültünün kaynağı pazar yerinde alışveriş yapan insanların sesleridir. Gündüz 68 dBA, akşam 63 dBA olan sınır değerlerin gündüz ölçümlerinin tamamında aşılmadiğ 1 , akşam ölçümlerinin tamamının ise sınır değerin üstünde olduğu gözlenmiştir.

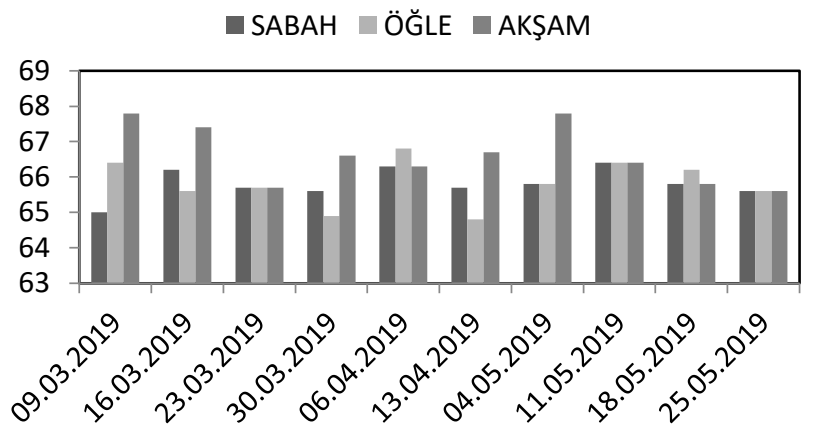

Şekil 9. Yedinci noktada ölçülen maksimum gürültü değerleri

Sekizinci ölçüm noktası pazar yerinin bitiş k1smindaki orta nokta olup, bu noktadaki gürültünün kaynağı pazar yerinde alışveriş yapan insanların sesleridir. Bu noktada ölçülen değerler Şekil 10'da gösterilmiş olup, maksimum değer 18.05.2019 tarihinde öğle saatlerinde $68.8 \mathrm{dBA}$ olarak elde edilmiştir. Yapılan ölçümlerin ÇGDYY'de gündüz $68 \mathrm{dBA}$, akşam $63 \mathrm{dBA}$ olarak verilen sınır değerlerin gündüz vakitlerinin çoğunda sağlandığı, akşam vakitlerinin tamamında sağlanamadığ gözlenmiştir (Şekil 10).

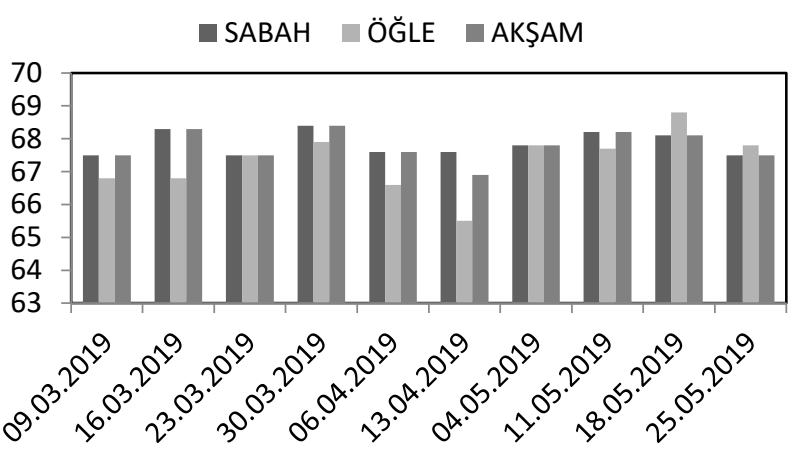

\section{Şekil 10. Sekizinci noktada ölçülen maksimum gürültü değerleri}

Dokuzuncu ölçüm noktası pazar yerinin bitiş kısmında yer alan diğer köşe noktadır. Bu noktadaki gürültünün kaynağı pazar yerinde alışveriş yapan insanların sesleridir. Ölçülen maksimum değer öğle saatlerinde 18.05.2019 tarihinde, akşam saatlerinde 16.03.2019 ve 30.03.2019 tarihlerinde 65.6 dBA olarak ölçülmüştür (Şekil 11). Yapılan gündüz ölçümlerinin 68 dBA sınır değerin altında olduğu, akşam ölçümlerinin ise $63 \mathrm{dBA}$ sinır değerinin üzerinde seyrettiği gözlenmiştir.

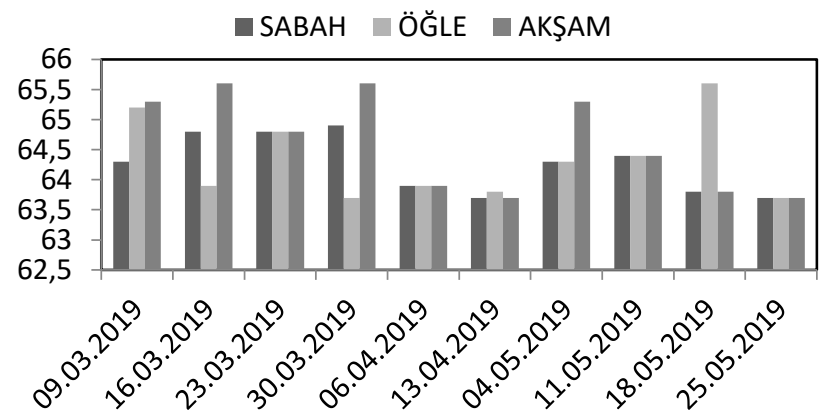

Şekil 11. Dokuzuncu noktada ölçülen maksimum gürültü değerleri

Onuncu nokta Görükle Semt Pazarı'nın arkasında kalan bir apartman dairesinin önüdür. $\mathrm{Bu}$ noktanın pazar yerine uzaklığı yaklaşık 12 m'dir. $\mathrm{Bu}$ noktada ölçülen maksimum değer 11.05.2019 tarihinde öğle saatlerinde 67.2 dBA'dır (Şekil 12). Bu noktadaki gürültünün kaynağ1 pazar yerinden gelen sesler ve apartmanın önündeki yoldan geçen araçlardır. Gündüz 68 dBA olan sinır değerin tüm ölçümlerde sağlandiğ 1 , akşam 63 dBA olan sınır değerin sadece 9.03.2019 tarihinde aşılmadı̆̆ görülmektedir. 


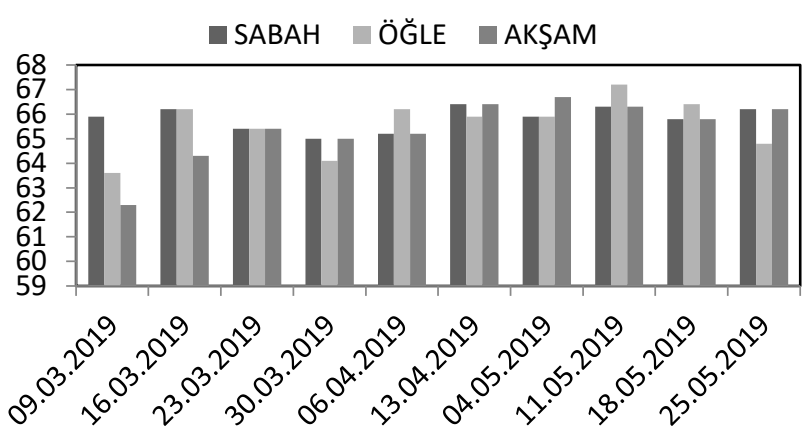

\section{Şekil 12. Onuncu noktada ölçülen maksimum} gürültü değerleri

Onbirinci ölçüm noktası Görükle Semt Pazarı girişi yakınında bulunan Görükle Hidayet Mescidi girişidir. Bu noktanın pazar yerine olan yakınlığı nedeniyle, buradaki gürültü pazara gelen insan seslerinden ve çoğunlukla araç geçişlerinden kaynaklanmaktadır. Mescid girişinde ölçülen maksimum değer 11.05.2019 tarihinde sabah ve akşam ölçümlerinde $73.2 \mathrm{dBA}$ olarak kaydedilmiştir. Gündüz 68 dBA ve akşam $63 \mathrm{dBA}$ olarak verilen sınır değerlerin gündüz ölçümlerinin çoğunda, akşam ölçümlerinin ise tamamında sağlanamadığı gözlenmiştir (Şekil 13).
Pazaryerinde yapılan gürültü ölçüm sonuçları incelendiğinde, sabah ölçümlerinde en yüksek değerin $80.2 \mathrm{dBA}$ ile 5. noktada, en düşük değerin ise $59.1 \mathrm{dBA}$ ile 10 . noktada ölçüldüğü görülmektedir (Tablo 1). Öğle vakti gerçekleştirilen ölçümler arasında kaydedilen en yüksek değer 5. noktada $80.7 \mathrm{dBA}$, en düşük değer 10. noktada 59.6 dBA'dır. Akşam ölçümleri arasında en yüksek değer $80.2 \mathrm{dBA}$ ile 5. noktada en düşük değer $58.2 \mathrm{dBA}$ ile 10 . noktada alınmıştır.

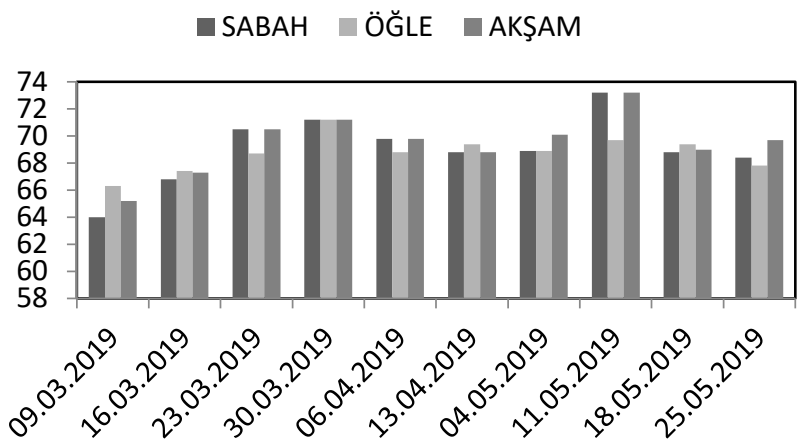

Şekil 13. Onbirinci noktada ölçülen maksimum gürültü değerleri

Tablo 1. Ölçüm vakitlerine göre minimum ve maksimum değerlerin karșılaştırılması

\begin{tabular}{lcccccc}
\hline \multirow{2}{*}{ Ölçüm noktaları } & \multicolumn{2}{c}{ Sabah } & \multicolumn{3}{c}{ Öğle } & \multicolumn{3}{c}{ Akşam } \\
\cline { 2 - 7 } & $\max$ & $\min$ & $\max$ & $\min$ & $\max$ & $\min$ \\
\hline 1. nokta & 72.6 & 63.8 & 71.5 & 63.9 & 71.5 & 64.2 \\
2. nokta & 70.4 & 63.3 & 69.7 & 63.3 & 69.7 & 63.1 \\
3. nokta & 69.8 & 64.5 & 68.9 & 62.3 & 69.9 & 64.5 \\
4. nokta & 69.6 & 64.3 & 68.9 & 64.5 & 70.1 & 64.3 \\
5. nokta & 80.2 & 68.1 & 80.7 & 68.8 & 80.2 & 69 \\
6. nokta & 73.2 & 68.5 & 73.2 & 63.3 & 73.5 & 67.3 \\
7. nokta & 66.4 & 62 & 66.8 & 62 & 67.8 & 62 \\
8. nokta & 68.4 & 62.9 & 68.8 & 62.1 & 68.4 & 63.4 \\
9. nokta & 64.9 & 62.3 & 65.6 & 62.2 & 65.6 & 62.4 \\
10.nokta & 66.4 & 59.1 & 67.2 & 59.6 & 66.7 & 58.2 \\
11. nokta & 73.2 & 62.7 & 71.2 & 62.2 & 73.2 & 62.7 \\
Ortalama & $\mathbf{7 0 , 4 6 4}$ & $\mathbf{6 3 , 7 7 3}$ & $\mathbf{7 0 , 2 2 7}$ & $\mathbf{6 3 , 1 1}$ & $\mathbf{7 0 , 6}$ & $\mathbf{6 3 , 7 3 6}$ \\
\hline
\end{tabular}


Vakitlere göre oluşan gürültü değerleri karşılaştırıldığında, maksimum gürültü değerleri ortalaması 70.6 dBA ile akşam vaktinde en yüksek; minimum gürültü değerleri ortalaması 63.11 dBA ile öğle vaktinde en düşük olarak hesaplanmıştır (Tablo 1). Bu çalışmaya benzer olarak, Yerli [29] Düzce kentinde yaya bölgelerinde oluşan gürültü farklarını incelediği çalışmada konutların yoğun olduğu bölge bulunan pazar yerinde birbirine eşit uzaklıktaki 6 noktada 100 m'lik aralıklarla bir yıllık süreç içerisinde gündüz saatlerinde haftalık gürültü ölçümleri yapmıştır. Sonuçlar aylık olarak değerlendirildiğinde en yüksek gürültü ortalamalarının ağustos ayında (70.2 dBA), en düşük gürültü ortalamalarının aralık ayında (55.6 dBA) hesaplandiğı; mevsim bazlı değerlendirmede ise en yüksek gürültü ortalamalarının yaz mevsiminde (67.95 dBA), en düşük gürültü ortalamaların kış mevsiminde (60.35 dBA) meydana geldiği bildirilmiştir.

\section{Sonuç}

Gürültü ile mücadele kapsamında ele alınan bu çalışmada, Bursa ili Nilüfer ilçesindeki Görükle'de bulunan bir pazar yeri içinde ve etrafındaki yerleşim yakınlarındaki noktalarda gürültü ölçümleri gerçekleştirilmiştir. $\mathrm{Bu}$ ölçümlerde mevcut yollarda ticari yapılar ile konutların yoğun olarak bulunduğu alanlar için ÇGDYY'de verilen gündüz $68 \mathrm{dBA}$, akşam 63 dBA [39] değerleri baz alınarak sonuçlar yorumlanmıştır. Sınır değerlerin üstünde kalan ve dolayısıyla gürültü açısından tehlike oluşturabilecek noktalar belirlenmiştir. Yapılan çalışmada ölçüm noktalarının tümünde özellikle akşam vakitlerinde meydana gelen gürültünün olması beklenen değerlerden daha yüksek seyrettiği görülmektedir. Pazar yerlerinden kaynaklanan gürültünün önlenmesi amaciyla alınabilecek önlemler aşağıda kısaca özetlenmiştir:

- Halkın ve pazar esnafinın televizyon, internet vb. çeşitli iletişim yayınları ile hazırlanacak afiş veya yazılı broşürlerle gürültü konusunda bilinçlenmesi sağlanarak, bu konuda duyarlılık oluşturulabilir.
- Pazarların kurulu olduğu günlerde trafik sorununu azaltmak amaciyla, trafiğin daha az yoğun olan yollardan akışı sağlanarak (sadece pazarın kurulu olduğu gün) pazar yeri yakınındaki araç trafiği azaltılabilir. Halkın pazar alışverişi sırasında araçların park edilmesinin karayolları kenarında tıkanıklık oluşturmaması amaciyla otopark oluşturulması, otoparkın mevcut fakat yeterli olmamasi durumunda belediyelerin park görevi üstlenecek alanlar oluşturarak halkın bu alanlara yönlendirilmesi sağlanabilir

(Hafta sonu pazarları için kamu binalarının bahçelerinin tahsis edilmesi v.b.)

- Kurulacak yeni pazar alanları için kentin gürültü haritası çıkarılarak, oluşabilecek gürültünün üzerinde tehlike oluşturabileceği hassas alanlardan uzakta inşa edilmesi sağlanabilir.

\section{Kaynaklar}

[1] Münir Cansın Özden, "Savaş gemilerinin pervane kaynaklı gürültü karakteristiklerinin hesaplamalı akışkanlar dinamiği yöntemleriyle incelenmesi”, Yüksek lisans tezi, İstanbul Teknik Üniversitesi Fen Bilimleri Enstitüsü, İstanbul, 2012.

[2] R. Ilgar, "Çanakkale şehir içi trafiğindeki araç kaynaklı gürültü kirliliğine yönelik ön çalışma”, ZfWT, vol. 4, no. 1, pp. 253-267, 2012.

[3] M. Pierrette, C. Marquis-Favre, J. Morel, L. Rioux, M.Vallet, S.Viollon and A. Moch, "Noise annoyance from industrial and road traffic combined noises: a survey and a total annoyance model comparison", J. Env. Psych., vol. 32 no. 2, pp. 178-186, 2012.

[4] G. Kürklü, G. Görhan and H. Burgan, "Çalışma hayatında gürültünün etkisi ve inşaat teknolojileri eğitimi açısından değerlendirilmesi”, Uluslararası Tekn. Bil. Der., cilt 5, say1 1, s. 35-22, 2013.

[5] F. Özyonar and İ. Peker, "Sivas kent merkezindeki çevresel gürültü kirliliğinin araştırılması”, Ekoloji, cilt 18, say1 69, s. 75-80, 2008.

[6] M. Mikaeili and Y. Memlük, "Ekoloji ve çevre açısından kompakt kent kavramı ve uygulama örnekleri”, Anadolu Doğa Bil. Der., cilt 4, sayı 2, s. 37-50, 2013 
[7] N. Akyıldız, Kulak Hastalıkları ve Mikrosirürjisi, Ankara: Ongun Kardeşler Matbaası, s. 587-598, 1980.

[8] Damla Azkeskin, "Gemi inşaatı sektöründe gürültü ve toz maruziyetinin değerlendirilmesi”, İş Sağlığı ve Güvenliği Uzmanlık Tezi, İş Sağlığı ve Güvenliği Genel Müdürlüğü, Ankara, 2016.

[9] Yasemin Ongun Funda, "Gürültüye maruziyetin işitme üzerindeki etkilerinin, sigara kullanımı ve kotinin ile ilişkisinin incelenmesi”, Uzmanlık Tezi, Abant İzzet Baysal Üniversitesi Kulak Burun Boğaz Anabilim Dalı, Bolu, 2012.

[10] N.E. Delikanlı, C. Yücedağ and A. Kapdı, "Bartın kentinde araç trafiğinden kaynaklı gürültü kirliliğ üzerine bir ön çalışma”, Mühendislik ve Teknoloji Bilimleri Dergisi, cilt 2, say1 2, s.21-40, 2014.

[11] K.T. Gürsel, M. Taner and E. Arslankan, "Gemiler açısından konfor parametrelerinin incelenmesi", Gemi ve Deniz Tekn., cilt 1, say1 203, s. 73-80, 2017.

[12] S. Vehid, E. Erginöz, E. Yurtseven, E. Çetin, S. Köksal and A. Kaymaz, "Hastane ortamı gürültü düzeyi”, TAF Prev Med Bull, cilt 11, sayı 4, s. 409414, 2011.

[13] E. Kol, E. İlaslan, S. İnce, "Yoğun bakım ünitelerinde gürültü kaynakları ve gürültü düzeyleri”, J. Turk. Soc. Intensive Care., sayı 13, s 122-128, 2015.

[14] N.T. Bayazıt, S. Küçükçifçi and B. Şan, "İlköğretim okullarında gürültüden rahatsızlığın alan çalışmalarına bağlı olarak saptanması", İTÜ Dergisi, cilt 10, say1 2, s. 169-181, 2011.

[15] M. Bulunuz, N. Bulunuz and J.K. Tuncal, "Akustik iyileştirme yapılmış bir okulda gürültü düzeyinin değerlendirilmesi”, Eğitimde Kuram ve Uyg., cilt 13, say1 4, s. 637-658, 2017.

[16] H. Yıldız, "İşyerlerinde gürültü haritası çıkarma yönteminin uygulanması, karşılaşılan sorunlar ve çözüm önerileri (bir tel fabrikası örneği)", Bilim Uzmanlığı Tezi, Hacettepe Üniversitesi Sağlık Bilimleri Enstitüsü, Ankara, 1996.

[17] F. Babalık, "İş Yerinde Gürültü ve Sağırlık Olasılığı", Mühendis ve Makina Der., Sayı 520, s. 1-7, Mayıs 2003.

[18] F. Ergün, R. Toprak and N. Aktürk, "Açık Ocak Maden İşletmelerinin Neden Olduğu Çevresel Gürültü’, Hacettepe Ün. Çevre Bilimleri, sayı 6, s. 1 9. 2004.

[19] İbrahim Çınar, "Madencilikte gürültü analizi, modellenmesi ve haritalanması", Doktora Tezi, Selçuk Üniversitesi Fen Bilimleri Enstitüsü, Konya, 2005 .
[20] Uğur Aydemir, “Gemi adamlarının gürültü maruziyetlerinin belirlenmesi ve alınabilecek önlemler", İş Sağlığı ve Güvenliği Uzmanlık Tezi, İş Sağlığı ve Güvenliği Genel Müdürlüğü, Ankara, 2015 .

[21] S. Viola, R. Grammauta, V. Sciacca, G. Bellia, L. Beranzoli, G. Buscaino, et al, "Continuous monitoring of noise levels in the Gulf of Catania (Ionian Sea): Study of correlation with ship traffic", Marine Poll. Bull., no. 121, pp. 97-103, 2017.

[22] Erkan Kalıpçı, "Giresun il merkezinde gürültü kirliliği ölçümü ve haritasının hazırlanması”, Yüksek Lisans Tezi, Selçuk Üniversitesi Fen Bilimleri Enstitüsü, Konya, 2007.

[23] A.E. Çerçevik, S. Yerel Kandemir, M.Ö. Yaylı and M. Çelik, "Şehir İçinde Temel Çalışması Yapılan Şantiyenin Konutta Oluşturduğu Gürültünün Araştırılması”, Uludağ Ün. Müh. Fak. Der., cilt 24, say1 1, s.151-160, 2019.

[24] W. Probst and B. Huber, "The Sound Power Level of Cities”, Sound and Vib., vol. 37, no. 5, pp.14-17, 2003.

[25] L. Güremen, “Amasya kent merkezi ana arter yollarında trafik gürültüsünün trafik koşul ve standartları yönüyle değerlendirilmesi”, J. of New World Sci. Academy-Eng. Sci., vol. 9, no. 4, pp. 2647,2014

[26] A.Yetiş, L. Gazigil, R. Yetiş, M. Doğan, M. Yiğit and B. Albayrak, "Determination of environmental noise from traffic: a case study from the rahva region", 11 . Ulusal Çevre Mühendisliği Kongresi, Bursa, 554564, (2015).

[27] A.E. Çerçevik, S. Yerel Kandemir, M.Yıldız and M. Çelik, "Bilecik ili şehir içi yollardan kaynaklı gürültü kirliliğinin ölçülmesi ve değerlendirilmesi”, Afyon Kocatepe Ün. Fen ve Müh. Bil. Der., sayı 18, s. 366$374,2018$.

[28] Ç.D. Akbulut and S. Önder, “Aksaray kenti açık-yeşil alanlarının nitelik ve nicelik yönünden incelenmesi”, Selçuk Tarım ve Gıda Bil. Der., cilt 25, sayı 1, s. 90 95, 2011.

[29] Ö. Yerli, "Düzce Kenti Yaya Bölgelerinin Gürültü Farklarının İncelenmesi”, Kastamonu Ün. Orman Fak. Der., cilt 16, sayı 1, s. 225-238, 2016.

[30] A. Aliağaoğlu, "Balıkesir şehrinde haftalık pazarlar: çekicilikler ve sorunlar”, Doğu Coğrafya Der., cilt 17, say1 27, s. 43-72, 2012.

[31] V. Çalışkan, "Bursa kent içi semt pazarları üzerine bir değerlendirme: merkez ilçe pazarlarından örnekler", Ulusal Coğrafya Kongresi, İstanbul, 125-132, (2005). 
[32] M. Yağbasan and A. Canpolat, "İş̧portacılıkta bağırmanın tüketiciye ulaşmadaki iletişimsel rolü (elazığ ili örneği)", Atatürk Ün. Sosyal Bil. Ens. Derg., cilt 8, say1 2, s. 377-392. 2010.

[33] L.G. Kaya, F. Aslan and B. Yılmaz, "Muğla-Dalyan turizminin özel çevre koruma bölgesi üzerine etkileri”, İnönü Ün. Sanat ve Tasarım Der., cilt 1, say1 3, s. 255-266, 2011.

[34] İnternet, URL: http://www.sbb.gov.tr/wpcontent/uploads/2018/11/09_Cevre.pdf (Erişim zamanı; Nisan, 18, 2020)

[35] R. Kaplanoğlu, URL: https://www.bursa.com/wiki/Gorukle (Erişim zamanı; Nisan, 21, 2020)

[36] İnternet, URL: https://www.haberler.com/goruklede-pazar-yeri-degisti-haberi/ (Erişim zamanı; Eylül, $16,2020)$
[37] İnternet, URL:

https://www.google.com/maps/place/G\%C3\%B6r\% C3\%BCkle+Pazar\%C4\%B1/@40.2285684,28.8423 $936,142 \mathrm{~m} /$ data $=! 3 \mathrm{~m} 1$ ! $1 \mathrm{e} 3 ! 4 \mathrm{~m} 8$ ! $1 \mathrm{~m} 2 ! 2 \mathrm{~m} 1$ ! $1 \mathrm{zZ} 8 \mathrm{O} 2 \mathrm{cs}$ O8a2xlIHBhemFyxLE!3m4!1s0x0:0x88ee02f44bed $886 ! 8 \mathrm{~m} 2 ! 3 \mathrm{~d} 40.2285949 ! 4 \mathrm{~d} 28.842502$ (Erişim zaman1; Nisan, 27, 2020)

[38] S. Özer, "Erzurum kent parklarındaki gürültü kirliliğinin belirlenmesi: Aziziye parkı örneğinde", Adnan Menderes Ün. Ziraat Fak. Der., cilt 11, sayı 2, s. 7-11, 2014.

[39] İnternet, URL:

http://www.cmo.org.tr/mevzuat/mevzuat_detay.php? kod=294 (Erişim zamanı; Mayıs, 12, 2020) 